(c) American Dairy Science Association, 2006.

\title{
Technical Note: Improved Extraction Method with Hexane for Gas Chromatographic Analysis of Conjugated Linoleic Acids
}

\author{
M. Y. Jung, ${ }^{\star} \dagger$ G.-B. Kim, ${ }^{*}$ E. S. Jang, † Y. K. Jung, ${ }^{*}$ S. Y. Park, ${ }^{*}$ and B. H. Lee ${ }^{\star} \ddagger^{1}$ \\ *Department of Food Science and Agricultural Chemistry, McGill University, \\ Ste-Anne de-Bellevue, QC, Canada H9X 3V9 \\ †Department of Food Science and Technology, Woosuk University, Samrea-Up, \\ Wanju-Kun, Jeonbuk Province 565-701, Republic of Korea \\ ¥Food Research and Development Centre, Agriculture and Agri-Food Canada, \\ St-Hyacinthe, QC, Canada J2S 8E3
}

\begin{abstract}
Extraction properties of different solvents (chloroform/methanol, hexane/isopropanol, and hexane) were studied for the gas chromatographic analysis of conjugated linoleic acids (CLA) from probiotic bacteria grown in de Man, Rogosa, and Sharpe medium. As compared with chloroform/methanol and hexane/isopropanol, hexane showed comparable extraction efficiency for CLA from unspent de Man, Rogosa, and Sharpe medium, but showed minimal extraction of oleic acid originated from the emulsifier in broth. The extraction efficiency of CLA by hexane was influenced by the broth $\mathrm{pH}$, showing the optimal $\mathrm{pH}$ of 7.0. Repeated extraction with hexane increased the yield. Extraction with hexane showed excellent recovery of spiked CLA from the spent broth with up to $97.2 \%$ (standard deviation of $1.74 \%$ ). This represents the highest recovery of CLA from culture broth ever reported. The sample size was also successfully reduced to $0.5 \mathrm{~mL}$ to analyze CLA from the broth without impairment of analytical data. This smaller sample size in the $1.5-\mathrm{mL}$ microcentrifuge tube using a small bench-top centrifuge reduced analytical time significantly.
\end{abstract}

Key words: conjugated linoleic acid, solvent extraction, gas chromatography, Bifidobacterium

Conjugated linoleic acids (CLA) are a group of naturally occurring isomers of linoleic acid containing a conjugated double bond system. Conjugated linoleic acids have been recognized for their beneficial functionality such as anticarcinogenicity, antiatherosclerotic and antidiabetic activities, fat partitioning, and bone strengthening activity (Watkins and Yong, 2001). Some of the ruminant and nonruminant bacteria show

Received March 8, 2005.

Accepted August 25, 2005.

${ }^{1}$ Corresponding author: byong.lee@mcgill.ca bioconverting activity of linoleic acid to conjugated linoleic acids (Jiang et al., 1998; Lin et al., 1999; Coakley et al., 2003; Oh et al., 2003; Rosberg-Cody et al., 2004). The main analytical method was gas chromatographic analysis after extraction of the fatty acids with solvent mixtures from broth, and derivatization of the fatty acids into their methyl esters. Here, we report a novel and efficient extraction method using hexane to analyze CLA in de Man, Rogosa, and Sharpe (MRS) broth with minimal extraction of oleic acid in culture broth.

To extract fatty acids from MRS broth by chloroform/ methanol, $4 \mathrm{~mL}$ of MRS broth was mixed well with $100 \mu \mathrm{L}$ of heptadecanoic acid $\left(\mathrm{C}_{17: 0}\right)$ solution $(50 \mathrm{mg}$ of heptadecanoic acid/ $5 \mathrm{~mL}$ of methanol) as an internal standard. Then, $6 \mathrm{~mL}$ of chloroform:methanol (2:1, vol/ vol) was added, mixed for $3 \mathrm{~min}$, and allowed to stand for $30 \mathrm{~min}$ before centrifugation $(1,900 \times g$ for $10 \mathrm{~min}$ at $5^{\circ} \mathrm{C}$ ). The upper layer was discarded and the lower layer (chloroform layer containing lipid) was collected. A trace of water was removed using sodium sulfate. To extract fatty acids by hexane/isopropanol, $4 \mathrm{~mL}$ of MRS broth was mixed with an internal standard (50 $\mathrm{mg}$ of $\mathrm{C}_{17: 0} / 5 \mathrm{~mL}$ of isopropanol), and isopropanol (2 $\mathrm{mL}$ ) was added. After MRS broth was vortexed for 30 $\mathrm{s}$, hexane $(4 \mathrm{~mL})$ was added, and the tube vortexed again for $3 \mathrm{~min}$. After $30 \mathrm{~min}$, the samples were centrifuged ( $1,900 \times g$ for $5 \mathrm{~min})$, and the upper hexane layer was collected. For extraction of fatty acids by hexane, $4 \mathrm{~mL}$ of MRS broth was mixed with $50 \mathrm{mg}$ of $\mathrm{C}_{17: 0} / 5$ $\mathrm{mL}$ of hexane as an internal standard. Hexane $(4 \mathrm{~mL})$ was added to this broth, and the samples were gently mixed for 10 min by tilting the tubes after screw capping. Caution is required not to vortex the mixture that breaks emulsion. After the mixtures were set aside for $30 \mathrm{~min}$, the samples were centrifuged at 1,900 $\times g$ for $5 \mathrm{~min}$, and the upper layer was collected. If necessary, the hexane extraction step was repeated up to 4 times. The lipid fraction was collected, and the solvent was evaporated under nitrogen gas at room temperature. 

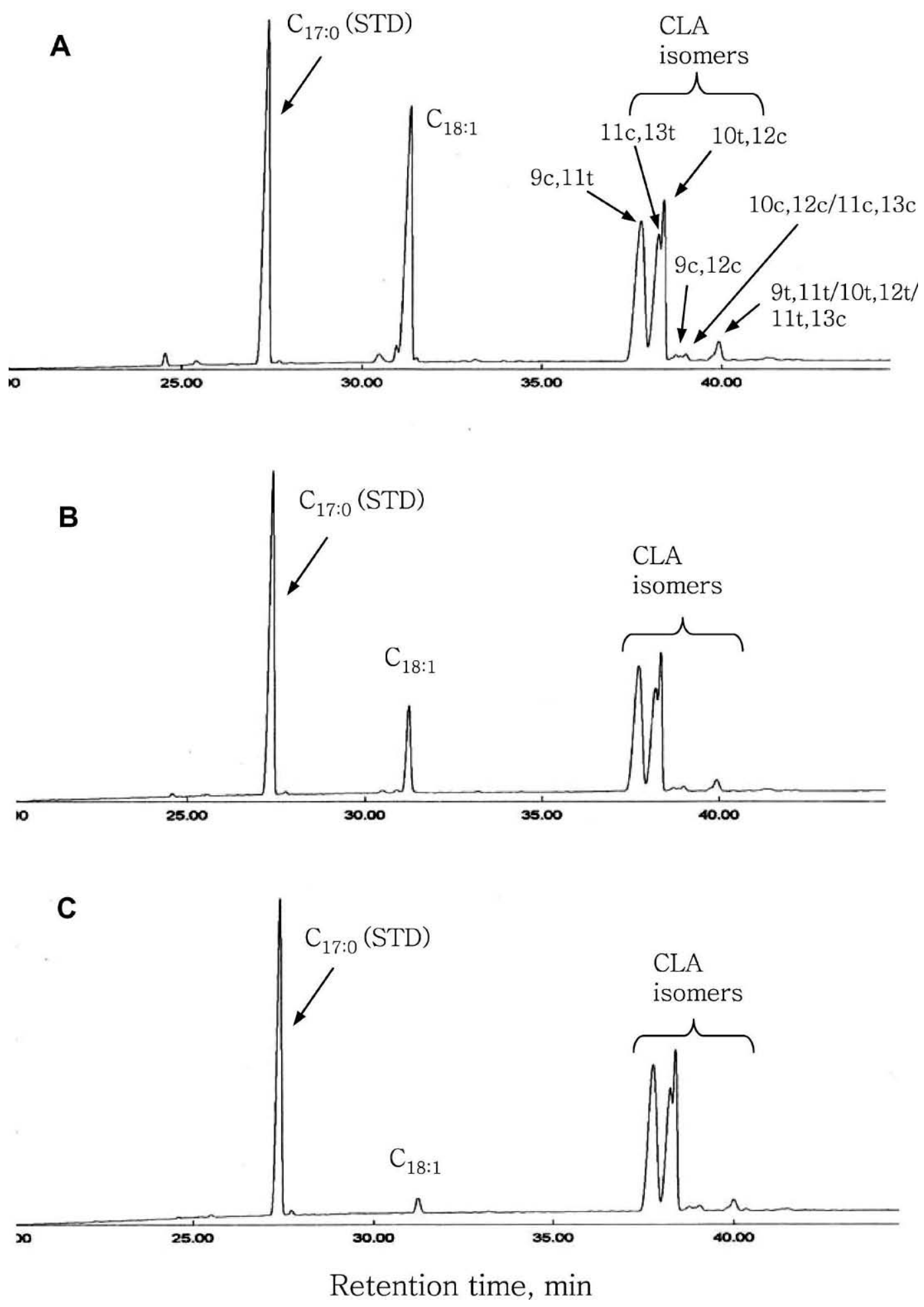

Figure 1. Gas chromatograms of methyl esters of fatty acids extracted from de Man, Rogosa, and Sharpe broth containing added authentic conjugated linoleic acids (500 $\mu \mathrm{g} / \mathrm{mL})$ using chloroform/methanol (A), hexane/2-propanol (B), and hexane (C). 
JUNG ET AL.

Table 1. Recovery rates of added conjugated linoleic acids (CLA, $500 \mu \mathrm{g} / \mathrm{mL}$ ) from the extracts from culture medium after $24 \mathrm{~h}$ of growth of Bifidobacterium breve ATCC 15698 at different $\mathrm{pH}$ values ${ }^{1}$

\begin{tabular}{|c|c|c|c|c|c|c|}
\hline & \multicolumn{5}{|c|}{ Recovered CLA isomers, $\mu \mathrm{g} / \mathrm{mL}$} & \multirow[b]{2}{*}{$\begin{array}{l}\text { Total CLA } \\
\text { recovery, \% }\end{array}$} \\
\hline & $9 \mathrm{c}, 11 \mathrm{t}$ & $\begin{array}{l}10 \mathrm{t}, 12 \mathrm{c} / \\
11 \mathrm{c}, 13 \mathrm{t}\end{array}$ & $\begin{array}{l}9 \mathrm{c}, 11 \mathrm{c} / \\
10 \mathrm{c}, 12 \mathrm{c} / \\
11 \mathrm{c}, 13 \mathrm{c}\end{array}$ & $\begin{array}{l}9 \mathrm{t}, 11 \mathrm{t} / \\
10 \mathrm{t}, 12 \mathrm{t} / \\
11 \mathrm{t}, 13 \mathrm{t}\end{array}$ & Total CLA & \\
\hline 4.7 & $136.1 \pm 7.1$ & $149.0 \pm 5.8$ & $2.95 \pm 0.9$ & $23.5 \pm 3.4$ & $311.5 \pm 17.2$ & $62.3 \pm 3.4$ \\
\hline 6.0 & $178.1 \pm 1.2$ & $188.0 \pm 9.0$ & $5.1 \pm 1.3$ & $29.6 \pm 0.5$ & $401.3 \pm 11.1$ & $80.3 \pm 2.2$ \\
\hline 6.7 & $192.2 \pm 5.3$ & $206.9 \pm 6.3$ & $5.3 \pm 1.7$ & $33.0 \pm 1.0$ & $437.4 \pm 12.9$ & $87.5 \pm 2.6$ \\
\hline 7.0 & $213.1 \pm 6.6$ & $217.3 \pm 8.4$ & $8.1 \pm 0.9$ & $38.4 \pm 1.3$ & $476.9 \pm 3.8$ & $95.4 \pm 0.8$ \\
\hline
\end{tabular}

${ }^{1}$ Mean values of duplicate or triplicate measurements with standard deviations.

Fatty acids were methylated with $1 \mathrm{~mL}$ of $1.0 \% \mathrm{HCl}$ in methanol solution at $60^{\circ} \mathrm{C}$ for $30 \mathrm{~min}$. After the reaction, $2 \mathrm{~mL}$ of saturated $\mathrm{NaCl}$ solution was added and the fatty acid methyl esters were extracted by addition of $0.5 \mathrm{~mL}$ of hexane. This extraction step was repeated twice and the extracted hexane was pooled into a $1.5-\mathrm{mL}$ microcentrifuge tube. The hexane was evaporated by a gentle stream of nitrogen and dissolved in 100 to $200 \mu \mathrm{L}$ of 2,2,4-trimethylpentane. The isolation of CLA was carried out by gas chromatography with a highly polar, fused-silica capillary column (SP2380 $100 \mathrm{~m} \times 0.25 \mathrm{~mm}, 0.25 \mu \mathrm{m}$ thickness, Supelco Inc., Bellefonte, PA) as previously reported (Jung et al., 2001; Jung and Jung, 2002).

Bifidobacterium breve ATCC 15698 was grown in cysteine-MRS broth with or without linoleic acid. This medium was inoculated with a fresh overnight culture $(1 \%, \mathrm{vol} / \mathrm{vol})$ and incubated for $24 \mathrm{~h}$ at $37^{\circ} \mathrm{C}$ in an anaerobic jar containing a gas pack (BBL GasPak Plus, $\mathrm{BD}$, Sparks, MD). After centrifugation $(1,900 \times g ; 5$ min) of the culture at room temperature, fatty acids in the supernatant were extracted and analyzed by gas chromatography. Figure 1 shows the partial gas chromatogram for the methyl esters of fatty acid obtained from MRS broth containing added authentic CLA by chloroform/methanol, hexane/2-propanol, and hexane. The identification of individual CLA isomers was based on our previous studies (Jung et al., 2001; Jung and Jung, 2002). The total CLA recovered from the broth containing $500 \mu \mathrm{g}$ of CLA/mL by chloroform/ methanol and hexane/2-propanol were $441.7 \pm 19.2$ and $428.0 \pm 4.5 \mu \mathrm{g} / \mathrm{mL}$, showing recovery rates of 88.3 and $85.6 \%$, respectively. The recovery rate of CLA with hexane/2-propanol was similar to those of previous reports (Jiang et al., 1996; Alonso et al., 2003). Both chloroform/methanol and hexane/2-propanol extraction methods showed high values of oleic acid, which was not added to MRS broth (Figure 1, A and B). The oleic acid contents obtained by chloroform/methanol and hexane/2-propanol were $218.8 \pm 29.5$ and $64.6 \pm$ $1.2 \mu \mathrm{g} / \mathrm{mL}$, respectively. The source of oleic acid was likely due to an emulsifier, Tween 80 (polyethylene sorbitan monooleate), which was present $(1,000 \mu \mathrm{g}$ of Tween $80 / \mathrm{mL}$ of broth) in MRS broth originally and added later as a CLA carrier for fatty acid preparation. To verify the origin of oleic acid, authentic Tween 80 (additional 1,000 $\mu \mathrm{g} / \mathrm{mL}$ broth) was added and the oleic acid contents were analyzed after the extraction with chloroform/methanol. The oleic acid content in MRS broth with added Tween 80 was 1.62 times higher than that of the original MRS broth, indicating Tween 80 in MRS as an origin of oleic acid. The chloroform/meth-

Table 2. Recovery of spiked conjugated linoleic acids (CLA; $500 \mu \mathrm{g} / \mathrm{mL}$ ) from $24 \mathrm{~h}$ growth culture of Bifidobacterium breve ATCC 15698 in de Man, Rogosa, and Sharpe (MRS) broth

\begin{tabular}{llllll}
\hline & \multicolumn{5}{c}{ CLA content, $\mu \mathrm{g} / \mathrm{mL}$} \\
\cline { 2 - 6 } & & $9 \mathrm{c}, 11 \mathrm{c} /$ & $9 \mathrm{t}, 11 \mathrm{t} /$ & Total \\
Sample & $9 \mathrm{c}, 11 \mathrm{t}$ & $10 \mathrm{t}, 12 \mathrm{c} /$ & $10 \mathrm{c}, 12 \mathrm{c} /$ & $10 \mathrm{t}, 12 \mathrm{t} /$ & CLA \\
\hline Spiked 1 & 531.6 & 216.0 & 8.9 & 63.5 & 820.1 \\
Spiked 2 & 520.0 & 226.5 & 7.4 & 63.2 & 817.1 \\
Spiked 3 & 519.9 & 223.9 & 8.1 & 65.6 & 817.5 \\
Mean value for spiked $^{\text {Mean value for original }}{ }^{1}$ & 523.9 & 22.1 & 8.1 & 64.1 & 818.2 \\
Spiked - original & 311.7 & 1.0 & 3.2 & 16.4 & 332.4 \\
\hline
\end{tabular}

${ }^{1}$ The values were obtained from the control without spiking in the broth after growth of $B$. breve in MRS broth containing $500 \mu \mathrm{g}$ of linoleic acid. 
anol system showed much higher oleic acid value than hexane/2-propanol (Figure 1A and 1B). We believe that the higher polarity of chloroform/methanol has favored the extraction of emulsifier, resulting in higher values of oleic acid. Thus, we hypothesized that by lowering the polarity, lower extraction of the emulsifier could be achieved. To prove this hypothesis, hexane (a solvent with very low polarity) was used to extract fatty acids from the broth (Figure 1C). The hexane extracted only small quantity of oleic acid (10.5 $\pm 0.4 \mu \mathrm{g} / \mathrm{mL}$ ), probably due to the lower solubility of Tween 80 (Figure 1C). The recovered CLA content from the MRS broth containing $500 \mu \mathrm{g}$ of CLA $/ \mathrm{mL}$ by hexane was $429.5 \pm 2.0 \mu \mathrm{g} / \mathrm{mL}$ of total CLA, showing a recovery rate of $85.9 \%$. The repeated extraction greatly increased the extraction efficiency of CLA. By the second extraction, the extraction efficiency reached $97.25 \%$, but thereafter, no further recovery of CLA was observed (data not shown). The repeated extraction with hexane did not considerably increase oleic acid extraction from broth.

The normal $\mathrm{pH}$ range of the spent broth after a 24$\mathrm{h}$ fermentation was 4.3 to 4.7 , due to the production of organic acids. To make it more realistic, the $\mathrm{pH}$ of MRS broth was adjusted to 4.6 with lactic acid solution. Whereas the first extraction with hexane in broth of $\mathrm{pH} 4.6$ (adjusted with lactic acid) showed only $66.7 \%$ efficiency, the extraction efficiency at $\mathrm{pH} 6.5$ (no lactic acid treated) was $85.9 \%$. This result clearly showed that $\mathrm{pH}$ greatly affected the extraction efficiency (data not shown).

The MRS broth was inoculated with a fresh overnight culture $(1 \%, \mathrm{vol} / \mathrm{vol})$ and incubated at $37^{\circ} \mathrm{C}$ for $24 \mathrm{~h}$ without linoleic acid. After $24 \mathrm{~h}$ incubation, the broth $\mathrm{pH}$ decreased from 6.5 to 4.2. We added authentic CLA $(500 \mu \mathrm{g} / \mathrm{mL})$ to this spent broth and carried out the extraction experiments with hexane. As expected, the extraction efficiency of CLA from the cultured media was significantly lower than that from the noncultured media, probably due to the $\mathrm{pH}$. Thus, the extraction experiments of CLA were done with hexane after the $\mathrm{pH}$ adjustments with $1 \mathrm{~N} \mathrm{NaOH}$ solution to 5.0, 6.5, and 7.0. As the $\mathrm{pH}$ increased, higher extraction of CLA was obtained as seen in Table 1. At $\mathrm{pH} 7.0$, the obtained recovery value was $95.4 \%$.

To study the repeatability of analytical data, the CLA isomer contents were analyzed in MRS broth supplemented with linoleic acid $(500 \mu \mathrm{g} / \mathrm{mL})$. After $24 \mathrm{~h}$ of growth at $37^{\circ} \mathrm{C}$, the culture $\mathrm{pH}$ in supernatant was 4.8 but was adjusted to $\mathrm{pH} 7.0$ with $1.0 \mathrm{~N} \mathrm{NaOH}$ to optimize the extraction efficiency. A portion of broth without $\mathrm{pH}$ adjustment was used as a control to compare the extraction efficiency. The CLA contents in control and spent broth with $\mathrm{pH}$ adjusted to 7.0 were
220.0 and $332.4 \mu \mathrm{g} / \mathrm{mL}$ of CLA, respectively. The significant difference in CLA contents in broth was attributed to the difference in extraction efficiency of CLA by hexane with different $\mathrm{pH}$. The percentage standard deviation for total CLA was only $1.54 \%(\mathrm{n}=5)$. The high precision of the data is likely due to the repeated extraction steps. The second extraction could make up for any technical error from the first extraction step. To verify the recovery rate, we spiked the authentic CLA $(500 \mu \mathrm{g} / \mathrm{mL})$ into the $\mathrm{pH}$-adjusted MRS broth $(\mathrm{pH}$ 7.0 ) and analyzed the recovery (Table 2). The recovery rate was $97.2 \%$, representing the highest CLA extraction from the culture media that ever reported. Previously reported values for recovery of CLA isomers were $83 \%$ (Lin et al., 1999), 89.4\% (Jiang et al., 1996), and $89.6 \%$ (Alonso et al., 2003).

To make the method simpler and to reduce the analysis time, the sample size was reduced to $0.5 \mathrm{~mL}$ in a $1.5-\mathrm{mL}$ microcentrifuge tube. The samples were extracted twice with $0.5 \mathrm{~mL}$ of hexane and derivatized. The solvent in the derivatized sample was similarly evaporated, dissolved in $100 \mu \mathrm{L}$ of 2,2,4-trimethylpentane, and the CLA contents analyzed by injecting 2 $\mu \mathrm{L}$ of each sample into a gas chromatograph. The data from the reduced sample size $(0.5 \mathrm{~mL})$ showed that the total CLA content was $335.7 \pm 3.4 \mu \mathrm{g} / \mathrm{mL}$, which is almost identical to that achieved using the larger sample size $(4 \mathrm{~mL} ; 332.4 \pm 5.1 \mu \mathrm{g} / \mathrm{mL}$ of total CLA). Statistical analysis using a $t$-test showed that 2 analytical values obtained from 2 sample sizes ( 4 vs. 0.5 $\mathrm{mL})$ were statistically the same $(P>0.20, \mathrm{df}=6)$.

\section{REFERENCES}

Alonso, L., E. P. Cuesta, and S. E. Gilliland. 2003. Gas chromatographic method for analysis of conjugated linoleic acids isomers (c9t11, t10c12, and t9t11) in broth media as application in probiotic studies. J. Chromatogr. Sci. 42:167-170.

Coakley, M., R. P. Ross, M. Nordgren, G. Fitzgerald, D. Devery, and C. Stanton. 2003. Conjugated linoleic acid biosynthesis by human-derived Bifidobacterium species. J. Appl. Microbiol. 94:138-145.

Jiang, J., L. Björck, and R. Fondén. 1998. Production of conjugated linoleic acid by dairy starter cultures. J. Appl. Microbiol. 85:95-102.

Jiang, J., L. Björck, R. Fondén, and M. Emanuelson. 1996. Occurrence of conjugated cis-9, trans-11-octadecadienoic acid in bovine milk; Effects of feed and dietary regimen. J. Dairy Sci. 79:438-445.

Jung, M. Y., and M. O. Jung. 2002. Identification of conjugated linoleic acids in hydrogenated soybean oil by silver ion-impregnated HPLC and gas chromatography-ion impacted mass spectrometry of their 4,4-dimethyloxazoline derivatives. J. Agric. Food Chem. 50:6188-6193.

Jung, M. O., S. H. Yoon, and M. Y. Jung. 2001. Effects of temperature and agitation rate on the formation of conjugated linoleic acids in soybean oil during hydrogenation process. J. Agric. Food Chem. 49:3010-3016.

Lin, T. Y., C. W. Lin, and C. H. Lee. 1999. Conjugated linoleic acid concentration as affected by lactic cultures and added linoleic. Food Chem. 67:1-5. 
Oh, D. K., G. H. Hong, Y. Lee, S. Min, H. S. Sin, and S. K. Cho. 2003. Production of conjugated linoleic acid by isolated Bifidobacterium strains. World J. Microbiol. Biotechnol. 19:907-912. Rosberg-Cody, E., R. P. Ross, S. Hussey, C. A. Ryan, B. P. Murphy, G. F. Fitzgerald, R. Devery, and C. Stanton. 2004. Mining the microbiota of the neonatal gastrointestinal tract for conjugated linoleic acid-producing bifidobacteria. Appl. Environ. Microbiol. 70:4635-4641.

Watkins, B. A., and L. Yong. 2001. Conjugated linoleic acid: The present state of knowledge. Pages 445-476 in Handbook of Nutraceuticals and Functional Foods. R. E. C. Wildman, ed. CRC Press, New York, NY. 